\title{
Pending Issues on Professionals' Well-Being: The Living and Working Together in Organization Perspective
}

\author{
Diletta Gazzaroli *(D) and Caterina Gozzoli (D) \\ Faculty of Psychology, Università Cattolica del Sacro Cuore, 20123 Milano, Italy; caterina.gozzoli@unicatt.it \\ * Correspondence: diletta.gazzaroli@unicatt.it
}

Citation: Gazzaroli, D.; Gozzoli, C. Pending Issues on Professionals' Well-Being: The Living and Working Together in Organization Perspective. Sustainability 2021, 13, 6868. https:// doi.org/10.3390/su13126868

Academic Editor: Hyo-Sun Jung

Received: 10 May 2021

Accepted: 11 June 2021

Published: 17 June 2021

Publisher's Note: MDPI stays neutral with regard to jurisdictional claims in published maps and institutional affiliations.

Copyright: (c) 2021 by the authors. Licensee MDPI, Basel, Switzerland. This article is an open access article distributed under the terms and conditions of the Creative Commons Attribution (CC BY) license (https:/ / creativecommons.org/licenses/by/ $4.0 /)$.

\begin{abstract}
Evolving research has increasingly recognized the crucial role of workers' well-being in contributing to organizational effectiveness and survival, also studying the different factors that can influence it. This paper explores how the construct of living and working together in organizations (LWTO) can face two current organizational challenges in terms of well-being: 1. keeping a balance between performance and organizational quality of life; 2 . managing the relationship with others' differences. Thus, LTWO is understood as the possibility (or absence) of a good exchange between workers (identity and otherness), related to a clear and shared work purpose within a specific organizational culture of difference that allows diversity of expression through generative conflict. We tested our model using the exploratory structural equation modeling methodology with EQS-6.3. Our results show how well-being is in fact influenced by LWTO and highlights in particular the central role played by work purpose.
\end{abstract}

Keywords: professional well-being; organizational well-being; living and working together; diversity; work purpose

\section{Introduction}

Well-being is a classic, challenging, and relevant topic; thus, research on well-being is rich and substantial [1-4]. How people feel in organizations can be a key point, not only with regard to the consequences of work-related stress on professionals but also for the survival and growth of the organization itself [2,3,5-19].

When talking about well-being, if we look at the current debate, we can see many studies with a complex approach to the study of this topic and some big questions still to be debated and on which we are going to insert our proposal.

\subsection{State of the Art and Two Relevant Issue}

In recent literature, as shown by Taheri et al. [4], there's an increasing number of theories and models aimed at describing and explaining how various factors influence well-being in organizations. Some of these are related to job characteristics or are at the individual level (e.g., meaningful work, self-control skills, psychological capital, job security, successful education, sense of control of affairs, and the ability to accept the realities of life), while others are at the relational and organizational level (e.g., organizational support, better interpersonal behavior, transformative leadership, organizational culture, sustainability of learning situations and rapid application of new knowledge, work-life balance issues, etc.). In other words, well-being is the result of the combination and the mutual influences of many causal factors.

Among the issues that have emerged over the years, we believe that two are particularly relevant and require further attention. The first of these concerns the fact that, when focusing on employees' well-being, researchers' and practitioners' recommendation has often been to shift attention away from factors usually associated with performance [11,20-22]. According to some authors $[11,23,24]$, this recommendation is supported by the fact that 
the dominant HRM approaches have focused on performance at the expense of employees' well-being.

This type of approach risks developing a sort of binary logic in HR practices, placing performance and well-being in two necessarily antagonistic positions $[5,25,26]$. Therefore, it is necessary to explore from a complex perspective the potential compatibilities between performance and well-being, accommodating the interests of both the ethical and the economic side [11,27-30]. As suggested by Ogbonnaya and Messersmith [26], researchers should explore how HRM systems can ensure adequate levels of employee performance while also not compromising well-being.

The second relevant issue is that, even if many studies have focused on individual, relational, and organizational dimensions, as yet little attention has been given to diversity [31-33]. Thus, organizations have a twofold condition, with constrictions on the one hand (i.e., employees have to work with colleagues that they do not choose) and opportunities on the other (i.e., employees can improve together). This means that relations and interactions with others are essential but often challenging organizational requirements [34]. Specifically, we refer to the fact that diversity (and its management) still represents a "double-edged sword", since, too often, diversity-focused initiatives and policies are implemented without the organizational culture (and so, the organizational actors) being ready to recognize diversity as a productive resource and as an element of value for the improvement of the professionals and the system as a whole. A consequence of this misalignment in terms of well-being is, therefore, a missed chance to link professionals' well-being to the enhancement of their specific skills, to the relationships with colleagues, and to the possibility of comparing and exchanging ideas, knowledge, and competences. Not only, in addition to losing this opportunity, organizations may face the reinforcement of diversity representation as a threat, an increase in criticality, and resistance against diversity; that is, an exacerbation of the perception of irreconcilability. According to us, this calls to the crucial and challenging role of the management of difference in organizations and to the possibility (or lack thereof) of an enhancement of differences without underestimating the efforts required.

\subsection{The Living and Working Together in Organization Proposal}

Considering the above reflections, in this work, we studied the link between professionals' well-being and living and working together in organizations (LWTO), which is positioned in the constructivism perspective [35].

Previous research highlighted that a good LWTO between workers helps to prevent forms of exclusion and malaise and to counteract destructive interpersonal conflicts; it also allows the enhancement of the specificities of each professional and the promotion of innovative ideas thanks to the comparison between minds at work [36-43].

LTWO is based on these main elements: the centrality of the relationship quality and exchanges between identity and otherness, related to a shared, clear, and sustainable work purpose within an organizational culture of difference (OCD) that allows diversity expression through generative conflict. Therefore, assuming that in organizations professionals are required to work together to produce (services or goods), it is obvious that a clear, shared, and sustainable work purpose can represent a common point of convergence for identification and motivation to act. In our perspective, the work purpose can be understood as a kind of boundary object [44]; in fact, it requires a shared organizational vision and a translation into clear organizational mandates. Thus, work purpose, both as a concrete and symbolic component of identification and motivation to act, constitutes the opportunity for professionals to achieve an exchange between identity and otherness. By "identity", we mean all that is known, perceived as "acquainted with" and that defines "familiar borders of safety" for an individual. Symmetrically, "otherness" calls the familiar into question because it represents what is unknown and frightening. This kind of process could also bring issues of conflict to light. However, as work purpose represents the element around which and for which identity and otherness must interact in organizations, it 
can provide the opportunity to deal with and manage conflict, increasing trust and clarifying mutual expectations. Of course, regarding an organizational context, this triangulation must be contextualized within a specific OCD to better understand the deep assumptions about how processes and relations should be treated. Thus, OCD, by allowing or rejecting the possibility to recognize and dialogue with differences, accelerates or inhibits the ability to promote generative work processes.

Through LTWO, we can approach the study of professional well-being by connecting it to different dimensions of organizational life. This is coherent with literature suggestion $[4,6]$ recommendation for a complex model approach, and it is in line with the works trying to reduce the risk of bias between well-being and performance, since diversity can serve as fuel for enriching relational exchanges.

Our hypothesis is that professionals' well-being is influenced by "exchange possibility", which (in turn) is predicted by three factors (connected to each other): OCD, work purpose, and organizational management. OCD informs organizational actors regarding how to handle the relationship with otherness and, thus-according to our approach-to feel comfortable and allowed (or not) to come into contact with their differences. Work purpose-according to our approach—represents a "space" wherein identity and otherness can confront each other on a concrete organizational mandate. This means that a common work purpose-in terms of meaning, feasibility, and congruence-allows to maintain the relation even when experiencing conflictual situations. As stated above, we considered three factors; thus, we also added organizational management. Organizational management "embodies" how assumptions about HR are translated into actions. In fact, we need to find HR policies that are coherent with the assumption that relationship quality between identity and otherness must be promoted and supported.

As shown by Figure 1, in our model the quality of the interpersonal exchange between identity and otherness is represented by the indirect measure exchange possibility and influences professionals' well-being. Thus, non-destructive conflict and chances for collaboration between professionals are linked to well-being to the extent that they represent the possibility of promoting an environment wherein every professional can find space and feel allowed to express his/her own uniqueness and perspective.

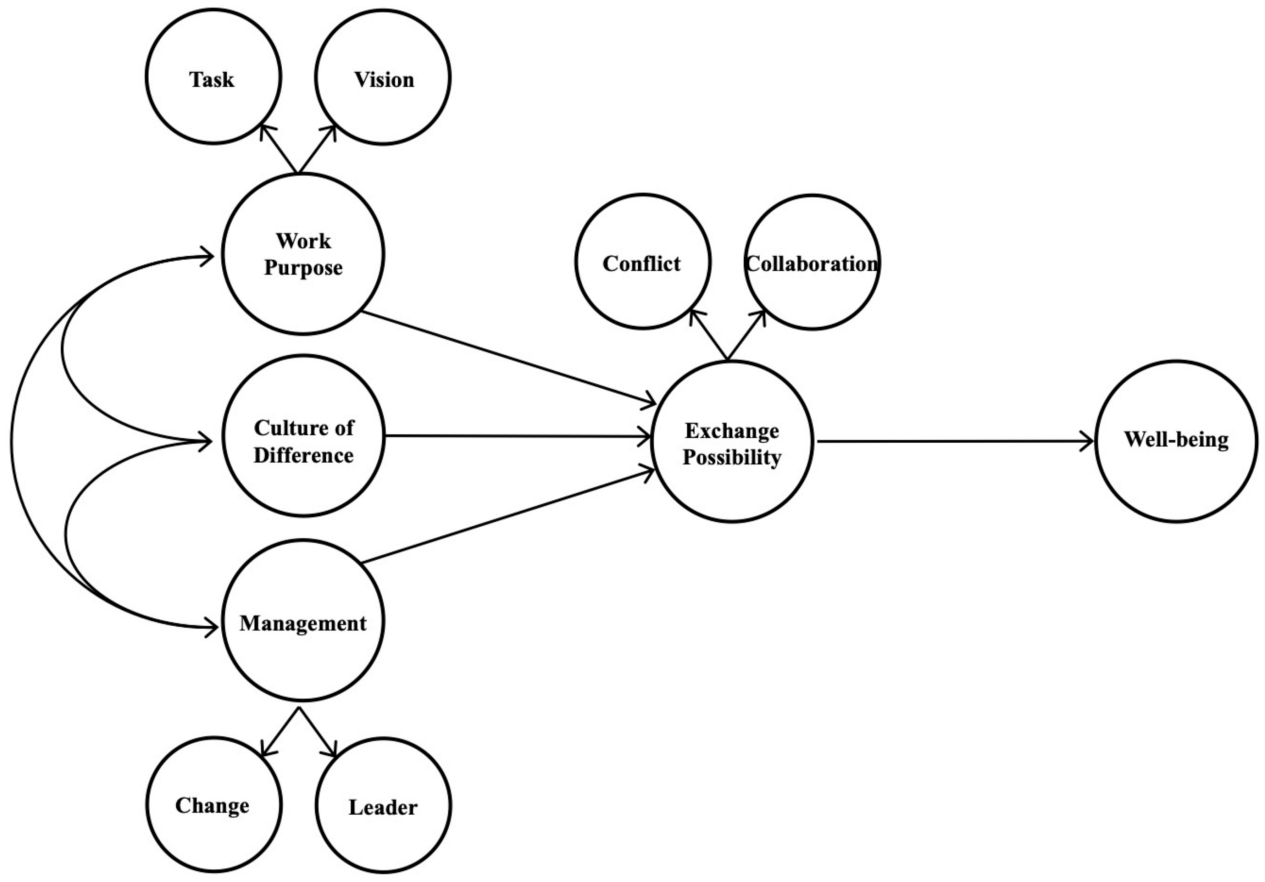

Figure 1. Model to test in the study. 
To summarize, assuming that an organization is a living system and, therefore, a system of relationships between differences aimed at producing, (goods or services), in this study, we want to understand if well-being is influenced by LWTO's key factors.

In the Measures section, the operationalization of the constructs will be presented.

\section{Materials and Methods}

\subsection{Aims and Scope}

Current organizational challenges in terms of well-being refer to: 1 . keeping a balance between performance and organizational quality of life; 2 . managing the relationship with others' differences. A good LWTO between workers makes it possible to prevent forms of exclusion and malaise and allows for the enhancement of the specificities of each professional, while promoting exchange between minds at work. For these reasons, with this study, we want to understand if well-being is linked with LTWO; consequently, we preferred to keep an explorative approach to test the possible correlations between LTWO and well-being.

\subsection{Sample and Procedure}

We collected data via questionnaire (with all closed-ended questions), either in a paper version (in the presence of a researcher if required by the organization) or online through a dedicated link on the Qualtrics platform. The questionnaire compiling required 35-40 min on average. All the 816 questionnaires collected were entered in a database for preliminary analysis; afterward, those with $60 \%$ or more answers missing were discarded.

Ultimately, there were 637 participants in the study (33.3\% male, 66.7\% female). Most participants who responded to the nationality question (n.643) were Italian (90.0\%). Participants who responded to the age question (n.637) were between 30 and 60 years of age, with an average age of 44.31 years $(\mathrm{SD}=8.01)$. Age group distribution was sufficiently balanced: $27.2 \%$ were $30-37$ years old; $23.9 \%$ were $38-43$ years old; $27.5 \%$ were $44-50$ years old; $21.5 \%$ were $51-60$ years old.

Since we did not want to deepen the well-being only in a particular organizational context, we decided to involve professionals working in different kinds of organization. Precisely, we can identify 3 main macro-groups: SMEs involved in the production industry $(26.4 \%)$, third sector organizations (35.9\%), and healthcare organizations (37.7\%). A convenience sampling criterion was used.

\subsection{Measures}

During questionnaire construction, we followed Fowler's guidelines [45]: using validated scales with reliability demonstrated in previous studies; avoiding the use of openended questions; using a five-point Likert scale to maximize the variance; choosing scales close as much as possible to our constructs. All the self-reported measure proposed were based on individual perceptions, even when they were referred to group or organizational dimensions. Below, the scales used in the study are listed (we used the Italian versions of the scales).

\subsection{Well-Being}

In this study, we interpreted "well-being" as an individual outcome experienced by professionals in daily life. We measured it using the "MBI-General Survey" from the Organizational Check-Up System (OCS) [46,47]. OCS is a program that measures the level of worker burnout within organizations to identify its main causes and to develop solutions for promoting engagement. OCS is based on precise theoretical assumptions, namely, that the greater the balance between the individual and the context, the greater the possibility of commitment and involvement of the person in the work, and vice versa. The "MBI-General Survey" (16 items) detects Maslach's three dimensions of job burnout: "emotional exhaustion" vs. "energy", "depersonalization" vs. "involvement", and "personal accomplishment" vs. "ineffectiveness". For this study, we used the Italian validation made 
by Borgogni, Galati, Petitta, Schweitzer [46] in collaboration with the developers of OCS. Specifically, "energy" and "involvement" seemed particularly relevant. In particular, the "energy" dimension appeared suitable to obtain data concerning perceptions on psychophysical conditions, while the "involvement" dimension appeared suitable to obtain data about perceptions of affective and emotional conditions.

\subsection{Exchange Possibility between Identity and Otherness}

We assumed that the "exchange possibility" implies the chance to avoid disruptive conflict while supporting generative debate and so to protect professionals' well-being. The exchange possibility was measured with two subscales, "collaboration" (6 items) and "social conflict" (6 items), from Majer's [48] Italian version of the Rahim Organizational Conflict Inventory-I. ROCI-I was created to measure the three dimensions of conflict within organizations and can be used for organizational diagnosis or to assess the extent of conflict in an organization, in one of its departments/functions and any changes over time. In the Italian version [48], the factors defined "collaboration" and "social conflict" are characterized by the presence of high saturation of items relating to harmony and conflict (regardless of whether the harmony or conflict is created within one's work group or between different work groups). All the closed-answer items measure the construct directly on a five-point Likert scale.

\subsection{Organizational Culture of Difference}

OCD represents an indicator of the organizational assumptions about diversity. We measured the construct with the Diversity Perspective Questionnaire vignettes (DPQ) [49], conceived to measure culture of diversity and its management in organizations. Authors [49] identified five possible perspectives in the literature on diversity management and ranged them from the maximum rejection of difference to its full appreciation and valorization. Each vignette refers to one of the five perspectives, characterized as follows:

- "Reinforcing homogeneity perspective": a diverse workforce must be avoided or even rejected;

- "Color-blind perspective": equal employment opportunities, with no interest in recognizing any potential differences;

- $\quad$ "Fairness perspective": equal and fair treatment specifically aimed to support minorities;

- "Access perspective": diversity is a business strategy to reach a wider customer base and international markets;

- "Integration and learning perspective": treating a diverse work environment as an opportunity for improvement for every professional.

Vignettes are introduced with this statement: "Below, you will find five short descriptions of organizational scenarios. Choose the one that, in your opinion, best represents your organization".

\subsection{Work Purpose}

Work purpose is a triangulation element between identity and otherness, so it must be clear and shared for all organizational actors. In fact, as proposed by our model, a group with clear and shared vision of its goals, will direct all its efforts toward developing an effective work process. We measured work purpose using the Italian validation of two team climate inventory (TCI) subscales [50]: "vision" and "task". TCI assumes that groups' innovative capacity is linked to four factors: "vision", "participative safety", "task orientation", and "support for innovation". In fact, based on this model, a group is facilitated to develop successful work processes when it has a clear and shared vision of the goals and when members feel free to contribute and support each other. The "vision" subscale (10 items) refers to the degree of clearness with which organizational and group goals and aims are perceived as shared, attainable, and measurable. The "task orientation" subscale (8 items) refers to a group's commitment to accomplish the highest possible 
performance level supported by monitoring procedures. All the closed-answer items measure the construct directly on a five-point Likert scale.

\subsection{Organizational Management}

Organizational management is an indicator of the processes through which organizational assumptions about how to handle diversity are translated into actions. We measured organizational management with two subscales "change" and "leadership", from the Areas of Worklife Survey of the Organizational Check-Up System [46,47] (see well-being section for more details on OCS). Specifically, "change" (10 items) measures perceptions of changes happened over the past six months, and "leadership" (5 items) refers to professionals" judgements on middle and top managers. The scales are composed of closed-answer items that measure the construct directly or through an "inverse" formulation on a five-point Likert scale.

\subsection{Data Analysis}

We applied exploratory structural equation modeling (ESEM) methodology with EQS-6.3 [51,52]. ESEM was chosen because it integrates the best aspects of CFA/SEM and traditional EFA. Hypotheses were tested through a two-stage procedure, according to Bentler-Weeks' approach [51]. In the first stage, we tested constructs' measurement properties with a confirmatory factor analysis (CFA) for all scales to check their degree of adequacy with respect to the study's sample. In the second stage, to verify the proposed relationships, we tested structural relationships among constructs. Degree of fit was verified according to these criteria: goodness-of-fit statistics (Chi-square statistic $\left(\chi^{2}\right)$, nonnormed fit index (NNFI), comparative fit index (CFI), standardized root mean square residual (SRMR), root mean square error of approximation (RMSEA), Raykov's reliability RHO $(\rho))$, discriminant reliability, and factor loadings. Test results are explained in the sections below.

\section{Results}

\subsection{Testing Measurement Properties}

Exchange Possibility between Identity and Otherness

"Collaboration" and "social conflict" are the first-order factors chosen to define "exchange possibility" construct. Therefore, we first conducted a CFA to check their adequacy degree with respect to the study's sample (see Table 1).

Table 1. Fit indices_-"collaboration" and "social conflict" subscale.

\begin{tabular}{|c|c|c|c|c|c|c|}
\hline Subscale & $\chi^{2}$ (gdl) $\ddagger$ & NNFI & CFI & SRMR § & RMSEA * & $\rho$ \\
\hline \multicolumn{7}{|l|}{ Collaboration } \\
\hline All items & $271.279(8)$ & 0.69 & 0.83 & 0.08 & 0.23 & 0.84 \\
\hline \multicolumn{7}{|c|}{ Removing items with lower saturation II } \\
\hline Without item 13 & $87.689(4)$ & 0.83 & 0.93 & 0.06 & 0.18 & 0.83 \\
\hline Without item 13-8 & $18.502(1)$ & 0.90 & 0.98 & 0.03 & 0.16 & 0.83 \\
\hline \multicolumn{7}{|l|}{ Social conflict } \\
\hline All items & $176.769(8)$ & 0.72 & 0.85 & 0.07 & 0.18 & 0.81 \\
\hline \multicolumn{7}{|c|}{ Removing items with lower saturation $\mathbb{I}$} \\
\hline Without item 5 & $93.287(4)$ & 0.78 & 0.91 & 0.05 & 0.14 & 0.80 \\
\hline
\end{tabular}


Table 1. Cont.

\begin{tabular}{lllllll}
\hline Subscale & $\chi^{2}$ (gdl) $\ddagger$ & NNFI & CFI & SRMR $\S$ & RMSEA * & $\rho$ \\
\hline Without item 5-19 & $3.343(1)$ & 0.98 & 0.99 & 0.01 & 0.06 & 0.80 \\
\hline
\end{tabular}

The following criteria have been applied to evaluate the analysis: $\ddagger$ According to Corbetta [53] the probability value for the Chi-square statistic is 0.00000 . However, since $\chi^{2}$ is sensitive to the sample size, with a large sample size, even when the model fits the data it is highly probable to have a $p$-value $<0.05$. $\S$ A value of and less than 0.08 could be considered a good fit [54]. * According to MacCallum et al. [55] with values from 0.80 to 0.10 the fit is mediocre but still acceptable. II Items' numbering corresponds to the original scale's order presentation.

Based on the final attempt results, for the "collaboration" subscale we included the items ${ }^{\text {II: }}$ collaboration1, collaboration2, collaboration18, and collaboration20. All items' saturation are between 0.53 and 0.83 . Based on the final attempt results, for the "social conflict" subscale we included the items ${ }^{\text {II: }}$ social-conflict4, social-conflict10, social-conflict9, social-conflict12, and social-conflict16. All the items' saturation are between 0.51 and 0.86 .

Since "exchange possibility" is a latent construct, resulting from the first-order factors "collaboration" and "conflict", we conducted a CFA to check the adequacy degree with respect to the study's sample (Table 2).

Table 2. Fit indices_-"relationship".

\begin{tabular}{lcccccc}
\hline Attempt & $\chi^{2}(\mathrm{gdl}) \ddagger$ & NNFI & CFI & SRMR § & RMSEA * & $\rho$ \\
\hline All items & $98.989(15)$ & 0.92 & 0.95 & 0.04 & 0.09 & 0.63 \\
\hline \multicolumn{2}{l}{ Removing items with lower saturation $\mathbb{I I}$} & & & & \\
\hline Without item 9 & $64.998(9)$ & 0.92 & 0.97 & 0.04 & 0.09 & 0.65
\end{tabular}

The following criteria have been applied to evaluate the analysis: $\ddagger$ According to Corbetta [53] the probability value for the Chi-square statistic is 0.00000 . However, since $\chi^{2}$ is sensitive to the sample size, with a large sample size, even when the model fits the data it is highly probable to have a $p$-value $<0.05$. § A value of and less than 0.08 could be considered a good fit [54]. * According to MacCallum et al. [55] with values from 0.80 to 0.10 the fit is mediocre but still acceptable. II Items' numbering corresponds to the original scale's order presentation.

Based on the results and the items' saturation (all between 0.53 and 0.89 ), in the final version, we considered all the items, except for social-conflict9.

\subsection{Work Purpose}

"Vision" and "task" are the first-order factors chosen to define "work purpose" construct. Therefore, we first conducted a CFA to check their adequacy degree with respect to the study's sample (see Table 3).

Table 3. Fit indices-"vision" and "task orientation" subscales.

\begin{tabular}{|c|c|c|c|c|c|c|}
\hline Subscale & $\chi^{2}(\mathrm{gdl}) \ddagger$ & NNFI & CFI & SRMR § & RMSEA * & $\rho$ \\
\hline \multicolumn{7}{|l|}{ Vision } \\
\hline All items & $701.331(34)$ & 0.76 & 0.82 & 0.08 & 0.18 & 0.90 \\
\hline \multicolumn{7}{|c|}{ Removing items with lower saturation II } \\
\hline Without item 9 & $468.643(26)$ & 0.81 & 0.86 & 0.07 & 0.16 & 0.90 \\
\hline Without item 9-8 & $381.572(19)$ & 0.82 & 0.88 & 0.07 & 0.17 & 0.90 \\
\hline Without item 9-8-10 & $254.544(13)$ & 0.84 & 0.90 & 0.06 & 0.17 & 0.90 \\
\hline $\begin{array}{l}\text { Without item } \\
9-8-10-7\end{array}$ & $224.398(8)$ & 0.82 & 0.90 & 0.06 & 0.20 & 0.90 \\
\hline
\end{tabular}


Table 3. Cont.

\begin{tabular}{lllllll}
\hline Subscale & $\chi^{2}($ gdl $) \ddagger$ & NNFI & CFI & SRMR § & RMSEA * & $\rho$ \\
\hline $\begin{array}{l}\text { Without item } \\
\text { 9-8-10-7-5 }\end{array}$ & $22.999(4)$ & 0.97 & 0.99 & 0.03 & 0.09 & 0.90 \\
\hline Task orientation & & & & & & \\
\hline All items & $146.492(19)$ & 0.95 & 0.96 & 0.03 & 0.10 & 0.92 \\
\hline
\end{tabular}

The following criteria have been applied to evaluate the analysis: $\ddagger$ According to Corbetta [53] the probability value for the Chi-square statistic is 0.00000 . However, since $\chi^{2}$ is sensitive to the sample size, with a large sample size, even when the model fits the data it is highly probable to have a $p$-value $<0.05$. $\S$ A value of and less than 0.08 could be considered a good fit [54]. * According to MacCallum et al. [55] with values from 0.80 to 0.10 the fit is mediocre but still acceptable. II Items' numbering corresponds to the original scale's order presentation.

Based on the final attempt results, for the "vision" subscale we included the items II: vision1, vision2, vision3, vision4, and vision6. All the items' saturation are between 0.64 and 0.90. Based on the final attempt results, for the "task" subscale we included the items ${ }^{\text {II: }}$ task11, task12, task13, task14, task15, task16, task17, and task18. All the items' saturation are between 0.65 and 0.88 .

Since "work purpose" is a latent construct, resulting from the first-order factors "vision" and "task", we conducted a CFA to check the adequacy degree with respect to the study's sample (Table 4).

Table 4. Fit indices-“work purpose”.

\begin{tabular}{lllllll}
\hline Attempt & $\chi^{2}(\mathrm{gdl}) \ddagger$ & NNFI & CFI & SRMR $\S$ & RMSEA * & $\rho$ \\
\hline All items & $382.851(60)$ & 0.92 & 0.94 & 0.07 & 0.09 & 0.94 \\
\hline
\end{tabular}

The following criteria have been applied to evaluate the analysis: $\ddagger$ According to Corbetta [53] the probability value for the Chi-square statistic is 0.00000 . However, since $\chi^{2}$ is sensitive to the sample size, with a large sample size, even when the model fits the data it is highly probable to have a $p$-value $<0.05$. $\S$ A value of and less than 0.08 could be considered a good fit [54]. * According to MacCallum et al. [55] with values from 0.80 to 0.10 the fit is mediocre but still acceptable.

Based on the results and items' saturation (all between 0.65 and 0.89 ), in the final version, we considered all the items.

\subsection{Organizational Management}

"Change" and "leadership" are the first-order factors chosen to define "organizational management" construct. Therefore, we first conducted a CFA to check their adequacy degree with respect to the study's sample (see Table 5).

Based on the final attempt result, for the "change" subscale we included the items II: change1, change4, change5, change6, change7, change8, change9, and change10. All the items' saturation are between 0.70 and 0.88 . Based on the final attempt result, for the "leadership" subscale we included the items II: leadership1, leadership2, leadership3, leadership4, leadership5, and leadership6. All items' saturation are between 0.69 and 0.86.

Since "organizational management" is a latent construct, resulting from the first-order factors "change" and "leadership", we conducted a CFA to check the adequacy degree with respect to the study's sample (Table 6).

Based on the results and the items' saturation (all between 0.68 and 0.88 ), in the final version, we considered all the items. 
Table 5. Fit indices-“change" and "leadership" subscales.

\begin{tabular}{lllllll}
\hline Subscale & $\chi^{2}$ (gdl) $\ddagger$ & NNFI & CFI & SRMR $\S$ & RMSEA * & $\rho$ \\
\hline Change & & & & & \\
\hline All items & $272.974(34)$ & 0.92 & 0.94 & 0.04 & 0.12 & 0.93 \\
\hline Removing items with lower saturation II & & & & \\
\hline Without item 2 & $201.688(26)$ & 0.94 & 0.95 & 0.03 & 0.11 & 0.93 \\
\hline Without item 2-3 & $146.753(19)$ & 0.95 & 0.96 & 0.03 & 0.10 & 0.93 \\
\hline Leadership & & & & & \\
\hline All items & $132.527(8)$ & 0.91 & 0.95 & 0.03 & 0.15 & 0.92 \\
\hline
\end{tabular}

The following criteria have been applied to evaluate the analysis: $\ddagger$ According to Corbetta [53] the probability value for the Chi-square statistic is 0.00000 . However, since $\chi^{2}$ is sensitive to the sample size, with a large sample size, even when the model fits the data it is highly probable to have a $p$-value $<0.05$. § A value of and less than 0.08 could be considered a good fit [54]. * According to MacCallum et al. [55] with values from 0.80 to 0.10 the fit is mediocre but still acceptable. II Items' numbering corresponds to the original scale's order presentation.

Table 6. Fit indices-"management processes".

\begin{tabular}{lllllll}
\hline Attempt & $\chi^{2}(\mathrm{gdl}) \ddagger$ & NNFI & CFI & SRMR $\S$ & RMSEA * & $\rho$ \\
\hline All items & $389.672(72)$ & 0.94 & 0.95 & 0.04 & 0.09 & 0.95 \\
\hline
\end{tabular}

The following criteria have been applied to evaluate the analysis: $\ddagger$ According to Corbetta [53] the probability value for the Chi-square statistic is 0.00000 . However, since $\chi^{2}$ is sensitive to the sample size, with a large sample size, even when the model fits the data it is highly probable to have a $p$-value $<0.05$. $\S$ A value of and less than 0.08 could be considered a good fit [54]. * According to MacCallum et al. [55] with values from 0.80 to 0.10 the fit is mediocre but still acceptable.

\subsection{Well-Being}

To check the scales' adequacy degree with respect to the study's sample, a CFA was conducted (see Table 7).

Table 7. Fit indices-“well-being" subscale.

\begin{tabular}{|c|c|c|c|c|c|c|}
\hline Subscale & $\chi^{2}$ (gdl) $\ddagger$ & NNFI & CFI & SRMR § & RMSEA * & $\rho$ \\
\hline \multicolumn{7}{|l|}{ Energy } \\
\hline All items & $40.135(4)$ & 0.92 & 0.97 & 0.03 & 0.1 & 0.87 \\
\hline \multicolumn{7}{|l|}{ Involvement } \\
\hline All items & $158.864(4)$ & 0.59 & 0.84 & 0.07 & 0.25 & 0.60 \\
\hline \multicolumn{7}{|c|}{ Removing items with lower saturation II } \\
\hline Without item 13 & $155.924(1)$ & -0.03 & 0.83 & 0.08 & 0.5 & 0.79 \\
\hline \multicolumn{7}{|c|}{$\begin{array}{l}\text { The following criteria have been applied to evaluate the analysis: } \ddagger \text { According to Corbetta [53] the probability } \\
\text { value for the Chi-square statistic is } 0.00000 \text {. However, since } \chi^{2} \text { is sensitive to the sample size, with a large sample } \\
\text { size, even when the model fits the data it is highly probable to have a } p \text {-value }<0.05 \text {. } \S \text { A value of and less than } \\
0.08 \text { could be considered a good fit [54]. * According to MacCallum et al. [55] with values from } 0.80 \text { to } 0.10 \text { the fi } \\
\text { is mediocre but still acceptable. II Items' numbering corresponds to the original scale's order presentation. }\end{array}$} \\
\hline
\end{tabular}

Based on the results, we decided to use only the subscale "energy", including all the items originally formulated (saturations between 0.70 and 0.81 ). 


\subsection{Model Testing}

Based on the results (see Table 8 and Figure 2), the model has good fit indices, which are statistically significant and satisfy the $\beta$ parameter.

Table 8. Fit indices model modified-well-being outcome.

\begin{tabular}{lllllll}
\hline Model & $\chi^{2}$ (gdl) $\ddagger$ & NNFI & CFI & SRMR $\S$ & RMSEA * & $\rho$ \\
\hline Model 1 & $1798.881(757)$ & 0.81 & 0.82 & 0.07 & 0.05 & 0.95 \\
\hline Model 2 (final) & $1760.331(716)$ & 0.92 & 0.92 & 0.07 & 0.05 & 0.96
\end{tabular}

The following criteria have been applied to evaluate the analysis: $\ddagger$ According to Corbetta [53] the probability value for the Chi-square statistic is 0.00000 . However, since $\chi^{2}$ is sensitive to the sample size, with a large sample size, even when the model fits the data it is highly probable to have a $p$-value $<0.05$. § A value of and less than 0.08 could be considered a good fit [54]. * According to MacCallum et al. [55] with values from 0.80 to 0.10 the fit is mediocre but still acceptable.

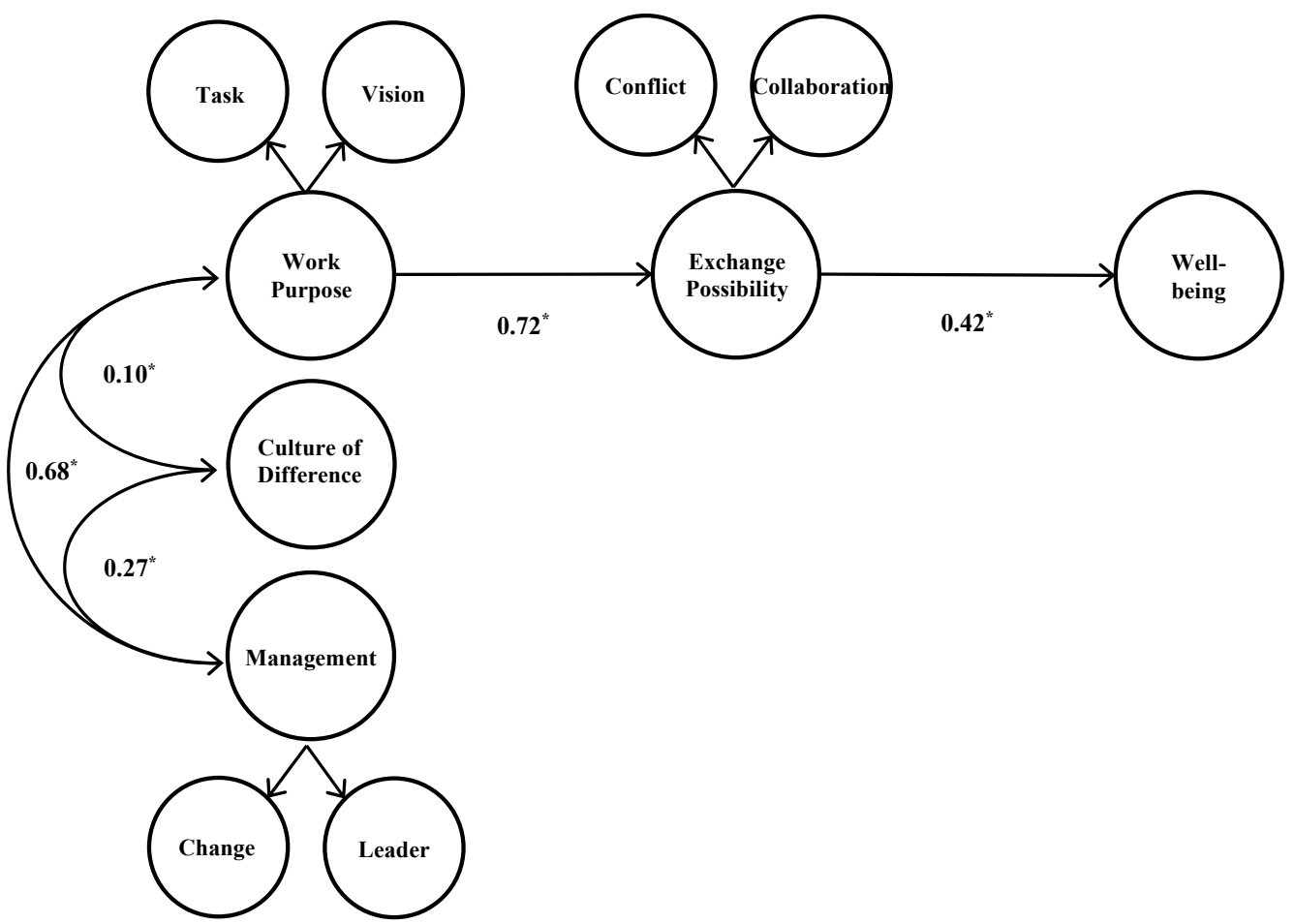

Figure 2. Final model. * All model's association are significant for $p<0.001$.

These results show that the theoretical model only partially fits the data. Regardless of their strength, all model associations are significant at $p<0.001$. With regard to the relations that constitute this model, some remarks can be made. The first of these concerns antecedent exogenous variables' correlations. The positive sign confirms that the three exogenous variables correlate with each other in the same direction. The correlation between organizational management and work purpose, with a $\beta$ value of 0.68 , is particularly strong while OCD's correlations with organizational management $(\beta=0.27)$ and work purpose $(\beta=0.10)$ are weaker. Results also confirm the association $(\beta=0.72)$ between work purpose and the exchange possibility as proposed by our model. Finally, results show that the impact of the exchange possibility on the outcome variable well-being is good $(\beta=0.42)$. Based on the analysis, our model has some interesting elements in support of the assumption that well-being is linked with the LWTO perspective. 


\section{Discussion}

Because it provides the opportunity to experience the professional dimension in terms of continuity and personal commitment, well-being is a prerequisite for organizational effectiveness and survival. "Organizations need to be aware that employees need to experience well-being, and that they play a crucial role in the promotion of well-being through HR practices" [30] (p. 12).

As pointed out earlier, assuming that an organization is a living system and, therefore, a system of relationships aimed at producing (goods or services), we believe that research works must fill two relevant gaps in the well-being literature: the tendency to put in contrast well-being and performance $[5,25,26]$; the fact that few studies consider the difference as a crucial element to promote (or, at least, sustain) well-being [31-33].

In this study, we have sought to understand if LWTO perspective could provide a complex perspective able to "sustain a generative and effective dialog" between well-being, performance, and diversity. As stated previously, through LWTO, we can approach the study of professional well-being by connecting it to different dimensions of organizational life. Indeed, a good LWTO between workers makes it possible to prevent forms of exclusion and malaise and allows for the enhancement of the specificities of each professional, while promoting performance through exchange between minds at work [36-43].

Our study showed that the exchange possibility between identity and otherness is predicted by the exogenous variable work purpose and seems to influence well-being. Specifically, well-being is linked with the relationship quality between identity and otherness, which is influenced by the presence (or absence) of a clear and shared work purpose. Thus, work purpose, triangulating with identity and otherness, promotes an exchanging possibility and, thus, allows to "get in touch" with differences to find a possible agreement. As evidenced by the model testing, a clear, shared, and sustainable work purpose proved to have an impact on exchange possibility. This finding is in line with the fact that work purpose is an essential part of professionals' daily experiences. as showed by the analysis, we can also say that, thanks to work purpose, the relationship between identity and otherness can be lived through cooperation and non-destructive conflict, thus safeguarding professionals' well-being.

In contrast, the associations of the OCD and organizational management factors with the exchange possibility were deleted, because the $\beta$ parameters could not be considered satisfying. However, the deletion of these associations does not necessarily imply that these factors could have a potential impact. Thus, with an in-depth model analysis, we can observe that they both have correlations (even though quite moderate) with work purpose. Organizational management, compared with OCD, has a higher correlation with work purpose. The higher correlation might depend on the fact that management processes are explicitly related to the management of each professional and to the overall system of human resources. Moreover, OCD can still be considered a novelty in the Italian context; thus, in Italian organizations, diversity still finds little space.

Through OCD and organizational management, professionals can be made aware of what can be considered legitimate and of the organizational direction about new possibilities and interests. Moreover, all these elements contribute to defining the degree of clearness, sharing, and sustainability of the work purpose.

Regarding the association between exchange possibility and well-being, even if the $\beta$ parameter could be not particularly high and satisfying, our results can still be considered aligned and coherent with our perspective assumptions. The $\beta$ parameter value obtained might depend on the fact that well-being could be primarily connected with individuals rather than with a group or organization. However, according to the analysis, we can say that the possibility to promote well-being is connected to a specific way of living in relation with otherness- that is, sharing cooperation and non-destructive conflict through a clear, shared, and sustainable work purpose.

In summary, the relationship between identity and otherness has an interesting significance in discussions of well-being in organizations, and this relationship deeply relies 
on the characteristics of work purpose. As a final point, attention should be given to the fact that work purpose, by contributing to the quality of the relationship between identity and otherness, promotes not only well-being but also more aware and effective work and production processes.

\subsection{Practical Implications}

When a point of convergence-that is, work purpose-is found, mutual expectations between employees and organization are explicit, HRM practices can be perceived positively, work processes become more manageable, and organizational confidence increases $[5,11,26]$.

By promoting effective commitment and aligning employees' interests more closely with organizational goals, work purpose supports not only well-being but also performance. Work purpose can support the process through which HRM practices communicate clear signals about organizational expectations from employees, thus promoting a good-quality environment and letting employees reciprocate through positive workplace attitudes and behavior. In summary, a clear, shared, and sustainable work purpose-in relation with other organizational LWTO factors-could help HRM systems to create a "win-win" situation for employees and the organization, in which working processes are facilitated, performance is strengthened, and a "well-being-supportive" environment is enhanced [26,38,39].

From this study, key points emerge both for the understanding of organizational life and for a possible critical analysis, in consideration of the following questions [56-58]: How much relational exchange is allowed? How much "space" can diversity and its expression find? Are the organizational mandates sustainable and clear enough for people to invest in them?

As a final word of caution, we wish to highlight that, since these elements are all connected to each other, in their management and operational translation they cannot be split but must all be considered together.

\subsection{Limitations and Future Directions}

Analyzing this study's limitations makes it possible to define some directions for future research. Firstly, even if our sample size can be considered quantitatively speaking adequate, it still does not offer a satisfying representativeness of the heterogeneity in the Italian working population. Thus, the majority of organizations involved in this study is characterized with a very homogeneous human resources composition (especially regarding nationality). For this reason, the model should be tested with a different sample composition. We are aware that the use of indirect measures could be a limitation of this study; however, we did not find direct measures consistent with the constructs of our model. Moreover, the RMSEA value in some scales' CFA is not satisfactory. However, we felt it was still interesting going on, since we used all Italian validated scales and all Cronbach's alpha values range from 0.70 and up. In fact, we had decided to apply the CFA just to guarantee a greater refinement of the scales and to remove the items with the lowest saturations with respect to our sample, which was very homogeneous in composition and belonged to different professional fields than those of the original validation. We suggest that future works should work in this direction. It would be also interesting to evaluate the effects on the model of group dynamics in organizations. It may also be worthwhile to continue the research with a qualitative approach, to point out all the different and deeper shades of this topic.

Lastly, future studies might include comparisons between different kinds of professionals and organizations to test whether different types of product/service have an impact. Effectively, in service realities a strong symbolic charge generally connotes work purpose, while in production enterprises, a strong business charge usually does so. However, although different kinds of organizations are characterized by different types of "products", they are all called to endorse a "well-being-oriented" environment to support professionals' and organizational growth. 
Author Contributions: Conceptualization, D.G. and C.G.; methodology, D.G. and C.G.; formal analysis, D.G. and C.G.; investigation, D.G.; writing-original draft preparation, D.G.; writingreview and editing, D.G. and C.G.; supervision, C.G. All authors have read and agreed to the published version of the manuscript.

Funding: This research received no external funding.

Informed Consent Statement: The study was conducted according to the guidelines of the Declaration of Helsinki and approved by CERPS (Commissione Etica per la Ricerca in Psicologia) of UNIVERSITÀ CATTOLICA DEL SACRO CUORE. Informed consent was obtained from all subjects involved in the study.

Data Availability Statement: All data collected during the study, as per privacy agreements, are saved in password-protected files managed by the research team.

Acknowledgments: The authors thank the organizations involved for collaborating in the research.

Conflicts of Interest: The authors report no conflict of interest.

\section{References}

1. Hirschle, A.L.T.; Gondim, S.M.G. Stress and well-being at work: A literature review. Public Health Sci. 2020, 25, $2721-2736$.

2. Ilies, R.; Aw, S.S.Y.; Pluut, H. Intraindividual models of employee well-being: What have we learned and where do we go from here? Eur. J. Work. Organ. Psychol. 2014, 24, 827-838. [CrossRef]

3. Ilies, R.; Pluut, H.; Aw, S.S.Y. Studying employee well-being: Moving forward. Eur. J. Work. Organ. Psychol. 2014, 24, 848-852. [CrossRef]

4. Taheri, F.; Pour, M.J.; Asarian, M. An exploratory study of subjective well-being in organizations-A mixed method research approach. J. Hum. Behav. Soc. Environ. 2019, 29, 435-454. [CrossRef]

5. Alfes, K.; Shantz, A.; Truss, C. The link between perceived HRM practices, performance and well-being: The moderating effect of trust in the employer. Hum. Resour. Manag. J. 2012, 22, 409-427. [CrossRef]

6. Bakker, A.B. Towards a multilevel approach of employee well-being. Eur. J. Work. Organ. Psychol. 2015, 24, 839-843. [CrossRef]

7. Bücker, S.; Nuraydin, S.; Simonsmeier, B.A.; Schneider, M.; Luhmann, M. Subjective well-being and academic achievement: A meta-analysis. J. Res. Pers. 2018, 74, 83-94. [CrossRef]

8. Caillé, A.; Courtois, N.; Galharret, J.-M.; Jeoffrion, C. The influence of empowering leadership on well-being at work and organizational commitment: Comparative study between an "empowering" organization and a "classic" organization. Psychol. Trav. Organ. 2020, 26, 247-261.

9. Nery, V.D.F.; Franco, K.S.; Neiva, E. Attributes of the Organizational Change and Its Influence on Attitudes Toward Organizational Change and Well-Being at Work: A Longitudinal Study. J. Appl. Behav. Sci. 2020, 56, 216-236. [CrossRef]

10. Grant, A.M.; Christianson, M.K.; Price, R.H. Happiness, Health, or Relationships? Managerial Practices and Employee Well-Being Tradeoffs. Acad. Manag. Perspect. 2007, 21, 51-63. [CrossRef]

11. Guest, D.E. Human resource management and employee well-being: Towards a new analytic framework. Hum. Resour. Manag. J. 2017, 27, 22-38. [CrossRef]

12. Lopez-Martin, E.; Topa, G. Organizational Culture and Job Demands and Resources: Their Impact on Employees' Wellbeing in a Multivariate Multilevel Model. Int. J. Environ. Res. Public Heal. 2019, 16, 3006. [CrossRef] [PubMed]

13. Lyubomirs, S. Why are some people happier than others? The role of cognitive motivational processes in well-being. Am. Psychol. 2001, 56, 239-249. [CrossRef]

14. Neiva, E.R.; Macambira, M.O.; Ribeiro, E.M.B.A. Management Practices, Well-being and Supportive Behavior. RAM 2020, 21, 1-27. [CrossRef]

15. Perko, K.; Kinnunen, U.; Tolvanen, A.; Feldt, T. Investigating occupational well-being and leadership from a person-centred longitudinal approach: Congruence of well-being and perceived leadership. Eur. J. Work. Organ. Psychol. 2015, 25, 1-15. [CrossRef]

16. Richter, A.; Näswall, K.; Bernhard-Oettel, C.; Sverke, M. Job insecurity and well-being: The moderating role of job dependence. Eur. J. Work. Organ. Psychol. 2013, 23, 816-829. [CrossRef]

17. Sorensen, G.; Peters, S.; Nielsen, K.; Nagler, E.; Karapanos, M.; Wallace, L.; Burke, L.; Dennerlein, J.T.; Wagner, G.R. Improving Working Conditions to Promote Worker Safety, Health, and Wellbeing for Low-Wage Workers: The Workplace Organizational Health Study. Int. J. Environ. Res. Public Heal. 2019, 16, 1449. [CrossRef]

18. Spreitzer, G.; Porath, C. Creating sustainable performance. Harv. Bus. Rev. 2012, 90, 92-99.

19. Weziak-Bialowolska, D.; Bialowolski, P.; Sacco, P.L.; VanderWeele, T.J.; McNeely, E. Well-Being in Life and Well-Being at Work: Which Comes First? Evidence From a Longitudinal Study. Front. Public Heal. 2020, 8, 103. [CrossRef]

20. Amrani, M.; Chaib, R.; Bouzaouit, A.; Ion, V. Well-being at work: A lever for sustainable performance in workplace. Min. Sci. 2020, 27, 89-104. [CrossRef] 
21. Peccei, R. Human Resource Management and the Search for the Happy Workplace; Erasmus Research Institute of Management (ERIM): Rotterdam, Holland, 2004.

22. Peccei, R.E.; Van De Voorde, K. Human resource management-well-being-performance research revisited: Past, present, and future. Hum. Resour. Manag. J. 2019, 29, 539-563. [CrossRef]

23. Kroon, B.; Van de Voorde, K.; Van Veldhoven, M. Cross-level effects of high-performance work practices on burn-out: Two counteracting mediating mechanisms compared. Pers. Rev. 2009, 38, 509-525. [CrossRef]

24. Ramsay, H.; Scholarios, D.; Harley, B. Employees and High-Performance Work Systems: Testing inside the Black Box. Br. J. Ind. Relat. 2000, 38, 501-531. [CrossRef]

25. Ho, H.; Kuvaas, B. Human resource management systems, employee well-being, and firm performance from the mutual gains and critical perspectives: The well-being paradox. Hum. Resour. Manag. 2019, 59, 235-253. [CrossRef]

26. Ogbonnaya, C.; Messersmith, J. Employee performance, well-being, and differential effects of human resource management subdimensions: Mutual gains or conflicting outcomes? Hum. Resour. Manag. J. 2019, 29, 509-526. [CrossRef]

27. Bryson, A.; Forth, J.; Stokes, L. Does employees' subjective well-being affect workplace performance? Hum. Relat. 2017, 70, 1017-1037. [CrossRef]

28. Luna-Arocas, R.; Danvila-Del-Valle, I. Does Positive Wellbeing Predict Job Performance Three Months Later? Appl. Res. Qual. Life 2020, 15, 1-15. [CrossRef]

29. Merriman, K.K. Extrinsic work values and feedback: Contrary effects for performance and well-being. Hum. Relat. 2016, 70, 339-361. [CrossRef]

30. Salas-Vallina, A.; Alegre, J.; López-Cabrales, A. The challenge of increasing employees' well-being and performance: How human resource management practices and engaging leadership work together toward reaching this goal. Hum. Resour. Manag. 2021, 60, 333-347. [CrossRef]

31. Dover, T.L.; Kaiser, C.R.; Major, B. Mixed Signals: The Unintended Effects of Diversity Initiatives. Soc. Issues Policy Rev. 2019, 14, 152-181. [CrossRef]

32. Köllen, T. Worshipping equality as organizational idolatry? A Nietzschean view of the normative foundations of the diversity management paradigm. Scand. J. Manag. 2020, 36, 101108. [CrossRef]

33. Nadiv, R.; Kuna, S. Diversity management as navigation through organizational paradoxes. Equal. Divers. Inclusion: Int. J. 2020, 39, 355-377. [CrossRef]

34. Mccord, M.A.; Joseph, D.L.; Dhanani, L.Y.; Beus, J.M. A meta-analysis of sex and race differences in perceived workplace mistreatment. J. Appl. Psychol. 2018, 103, 137-163. [CrossRef] [PubMed]

35. Pearce, W.B. Communication and Social Construction: Claiming Our Birthright. In Socially Constructing Communication; Hampton Press: New York, NY, USA, 2009; pp. 33-56.

36. Frascaroli, D.; Gozzoli, C.; D'Angelo, C. When training becomes incentive for generative living and working together in organizations. World Futures 2016, 72, 1-15. [CrossRef]

37. Gazzaroli, D.; Gozzoli, C.; Gardey, G.S. The Living and Working Together Perspective on Creativity in Organizations. Front. Psychol. 2019, 10. [CrossRef] [PubMed]

38. Gozzoli, C. Living and Working Together in Organizations: Theme Relevance-An Introduction. World Futures 2016, 72, $219-221$. [CrossRef]

39. Gozzoli, C. Living and Working Together in Organizations: Traces and Ways. World Futures 2016, 72, 222-233. [CrossRef]

40. Gozzoli, C.; Gazzaroli, D.; D'Angelo, C. Who Cares for Those Who Take Care? Risks and Resources of Work in Care Homes. Front. Psychol. 2018, 9. [CrossRef]

41. Gorli, M.; Ripamonti, S.C.; Galuppo, L. Change and Management of Complex Services: The Ethno-narrative Form to Support Good Living and Working Together. World Futures 2016, 72, 284-303. [CrossRef]

42. Marta, E.; Marzana, D.; Aresi, G.; Pozzi, M. When living and working well together in organizations changes into good social coexistence: The Talent Club case. World Futures 2016, 72, 1-18. [CrossRef]

43. Tamanza, G.; Gozzoli, C.; Gennari, M. Revealing the Difference: Between Conflict Mediation and Law Enforcement-Living and Working Together as a Conceptual and Methodological Turning Point to Activate Transformation in a Juvenile Criminal Mediation Service. World Futures 2016, 72, 1-20. [CrossRef]

44. Star, S.L. This is Not a Boundary Object: Reflections on the Origin of a Concept. Sci. Technol. Hum. Values 2010, 35, 601-617. [CrossRef]

45. Fowler, F.J. Survey Research Methods; SAGE Publications: London, UK, 2002.

46. Borgogni, L.; Galati, D.; Petitta, L. Organizational Checkup System: Come prevenire il Burnout e Costruire L'engagement; Giunti Psychometrics: Firenze, Italy, 2005.

47. Leiter, M.P.; Maslach, C. Preventing Burn-Out and Building Engagement: A Complete Program for Organizational Renewal; Jossey-Bass Inc.: San Francisco, CA, USA, 2000.

48. Majer, V. Il Conflitto: Teorie e Modelli. In ROCI: Rahim Organizational Conflict Inventory; Rahim, M.A., Ed.; Giunti Psychometrics: Firenze, Italy, 1995.

49. Podsiadlowski, A.; Gröschke, D.; Kogler, M.; Springer, C.; van der Zee, K. Managing a culturally diverse workforce: Diversity perspectives in organizations. Int. J. Intercult. Relat. 2013, 37, 159-175. [CrossRef]

50. Ragazzoni, P.; Baiardi, P.; Zotti, A.M.; Anderson, N.; West, M. Research note. J. Manag. Psychol. 2002, 17, 325-336. [CrossRef] 
51. Byrne, B.M. Structural Equation Modeling with EQS: Basic Concepts, Applications, and Programming, 2nd ed.; Lawrence Erlbaum Associates, Publishers: London, UK, 2006.

52. Marsh, H.W.; Morin, A.J.; Parker, P.D.; Kaur, G. Exploratory Structural Equation Modeling: An Integration of the Best Features of Exploratory and Confirmatory Factor Analysis. Annu. Rev. Clin. Psychol. 2014, 10, 85-110. [CrossRef] [PubMed]

53. Corbetta, P. Social Research: Theory, Methods and Techniques; SAGE Publications: London, UK, 2003.

54. Hu, L.T.; Bentler, P.M. Cutoff criteria for fit indexes in covariance structure analysis: Conventional criteria versus new alternatives. Struct. Equ. Model. Multidiscip. J. 1999, 6, 1-55. [CrossRef]

55. MacCallum, R.C.; Roznowski, M.; Necowitz, L.V. Model modifications in covariance srtucture analysis: The problem of capitalization on chance. Psychol. Bull. 1996, 111, 490-504. [CrossRef] [PubMed]

56. D'Angelo, C.; Gozzoli, C.; Gazzaroli, D.; Mezzanotte, D. Experiences and consequences on prison police's well-being. World Futures 2018, 74, 360-378. [CrossRef]

57. Scaratti, G.; Gorli, M.; Galuppo, L.; Ripamonti, S.; Gozzoli, C. The social relevance and social impact of knowledge and knowing. Manag. Learn. 2014, 45, 360-362. [CrossRef]

58. Scaratti, G.; Galuppo, L.; Gorli, M.; Gozzoli, C.; Ripamonti, S. The social relevance and social impact of knowledge and knowing. Manag. Learn. 2017, 48, 57-64. [CrossRef] 